\title{
Effects of Cinnamomum cassia extract on oxidative stress, immunreactivity of iNOS and impaired thoracic aortic reactivity induced by type II diabetes in rats
}

\author{
Gözde Atila Uslu ${ }^{1 *}$, Volkan Gelen ${ }^{1}$, Hamit Uslu², Hasan Özen ${ }^{3}$ \\ ${ }^{1}$ Department of Physiology, Faculty of Veterinary Medicine, University of Kafkas, Kars-Turkey, ${ }^{2}$ Department of Health \\ Care Services, Ataturk Health Vocational School, University of Kafkas, Kars-Turkey, ${ }^{3}$ Department of Pathology, Faculty of \\ Veterinary Medicine, University of Kafkas, Kars-Turkey
}

\begin{abstract}
Type II diabetes is known to cause neuropathy, nephropathy and retinopathy. However, cardiovascular disorders associated with diabetes have been ignored. In traditional medicine, cinnamon (Cinnamomum cassia) bark has been used for its abilities to relieve fever, inflammation and chronic bronchitis. In the present study, the effect of Cinnamomum cassia extract $(\mathrm{CN})$ on the thoracic aorta in an experimental type II diabetes model was investigated. In rats administered with nicotinamide + streptozotocin, significant endothelial dysfunction and oxidative stress were characterised by increased inducible nitric oxide synthase (iNOS) and decreased insulin/proinsulin levels. This impairment was prevented by administering $1000 \mathrm{mg} / \mathrm{kg}$ metformin or $500-1000-1500 \mathrm{mg} / \mathrm{kg} \mathrm{CN}$. CN administration attenuated the inflammatory response by decreasing the levels of malondialdehyde (MDA), Nitric oxide (NO) and increasing Glutathione peroxidase (GPx), glutathione (GSH). In addition, $\mathrm{CN}$ administration was shown to cause down-regulating effects on iNOS in thoracic aorta. These findings reveal that $\mathrm{CN}$ could prevent chronic complications of experimentally induced type II diabetes by attenuating inflammation, oxidant/antioxidant imbalance, and normalised contraction and relaxion responses in the thoracic aorta.
\end{abstract}

Keywords: Type II diabetes. Oxidative stress. iNOS. Thoracic aorta reactivity. Cinnamomum cassia/ effects.

\section{INTRODUCTION}

Diabetes mellitus is associated with numerous complications that are considered as major health problems in the developed world. For instance, it increases susceptibility to many diseases including cardiovascular issues. It is estimated that more than $75 \%$ of deaths in diabetes patients are caused by cardiovascular diseases (Xu, Zou, 2009). Diabetic patients are at an increased risk of three major macrovascular diseases, namely peripheral vascular disease, coronary heart disease, and stroke (Zou, Cohen, Ullrich, 2004; Scirica et al., 2013). Endothelial cells are thought to potentially regulate basal vascular tone and reactivity in physiological and pathological conditions (Furchgott, Vanhoutte, 1989; Nitenberg et al., 1993) and prolonged exposure to hyperglycemia in diabetic patients

*Correspondence: G. A. Uslu. Department of Physiology, Faculty of Veterinary Medicine, University of Kafkas, Kars-Turkey. E-mail: gzd.gozde@hotmail.com increases the risk of endothelial damage (Macías et al., 2014).

Endothelial damage and its mechanism in type II diabetes remains to be understood. However, it has been suggested that endothelial damage may be due to decreased endothelium-derived relaxing factor (EDRF) production and hence diminished smooth muscle response to EDRF (De Vriese et al., 2000). Alternative mechanisms that have been suggested include: Deterioration of the vasodilating mechanism of bradykinin (Kiff et al., 1991), abnormalities at the G-protein level and impaired nitric oxide mediated vasodilating mechanism (Williams et al., 1996), and overproduction of endothelium-derived contracting factor (Mayhan, Simmins, Sharpe, 1991).

Cinnamon bark and twigs have long been used in traditional Chinese herbal medicine for their therapeutic abilities, lowering fever, inflammation, chronic bronchitis, and for improving blood circulation (Barceloux, 2009). Cinnamon consumption has also been shown to 
increase glucose uptake and glycogen synthesis (ImparlRadosevich et al., 1998) and have insulin-mimetic effects (Jarvill-Taylor, Anderson, Graves, 2001). In the current study, effects of Cinnamon cassia extract on oxidative stress markers and thoracic aorta in experimentally type II diabetes mellitus induced rat models were investigated.

\section{MATERIAL AND METHODS}

Sixty female Sprague-Dawley rats weighing 200$250 \mathrm{~g}$ were used in this study. Animals were housed under a 12:12 h light-dark cycle in a controlled environment temperature $\left(23{ }^{\circ} \mathrm{C} \pm 2{ }^{\circ} \mathrm{C}\right)$ and humidity $(55 \% \pm 5 \%)$. Standard rat feed and water were provided ad libitum throughout the experimental period. All animal procedures were conducted in accordance with the guidelines of Kafkas University Animal Ethics Committee (2014/003). The rats were equally divided into six groups, namely Normoglycemic Control (NC), Diabetes (DC), diabetes plus $500 \mathrm{mg} / \mathrm{kg}$ Cinnamomum cassia extract (CN 500), diabetes plus $1000 \mathrm{mg} / \mathrm{kg} \mathrm{CN}$ (CN 1000), diabetes plus $1500 \mathrm{mg} / \mathrm{kg}$ $\mathrm{CN}$ (CN 1500), and Diabetes plus metformin (M).

\section{Induction of type II diabetes}

Type II diabetes was induced using a previously documented method (Masiello et al., 1998). Rats received an intraperitoneal injection of a single dose nicotinamide (NAD, $230 \mathrm{mg} / \mathrm{kg}$ ) followed by an intravenous injection of streptozotocin (STZ, $65 \mathrm{mg} / \mathrm{kg}$ ) (Masiello et al., 1998). Rats were considered diabetic if their fasting blood glucose levels were $>200 \mathrm{mg} / \mathrm{dL} 72 \mathrm{~h}$ after NAD plus STZ administration.

\section{Experimental design}

$\mathrm{NC}$ rats were given $500 \mu \mathrm{L}$ dimethyl sulfoxide (DMSO) orally for 35 days. In the DC group, diabetes was induced using the aforementioned method, and DMSO was administered as in the NC group. While the CN 500, CN 1000, and CN 1500 groups were administered 500, 1000, and $1500 \mathrm{mg} / \mathrm{kg}$ Cinnamomum cassia extract $(\mathrm{CN})$, respectively, via orogastric tubes for 35 days after hyperglycemia had stabilised 7 days post-injections.. The M group, received oral metformin (1000 mg/kg) for 35 days.

\section{Preparation of cinnamon extract}

Cinnamomum cassia barks were supplied by a local market and were grounded into fine powder. A sample of
$50 \mathrm{~g}$ was used, and the extraction was accomplished in Soxhlet apparatus for 6 hours. The remaining liquid was left to evaporate and a $9.5 \mathrm{~g}$ dry extract was obtained. The dry extract was dissolved in DMSO and the daily doses were calculated from the stock solution.

\section{Biochemical analysis}

At the end of the experimental period, the rats were sacrificed by $0.4 \mathrm{~mL} / \mathrm{kg}$ intramuscular pentobarbital sodium injections followed by cervical dislocation. Thoracic aorta of rats were excised, washed with physiological saline and homogenised in phosphate buffered saline $\mathrm{pH}$ 7.4. Serum levels of nitric oxide (NO), malondialdehyde (MDA), reduced glutathione (GSH), and glutathione peroxidase (GPx) were determined spectrophotometrically according to previously described methods (Miranda, Espey, Wink, 2001; Placer, Cushman, Johnson, 1966; Sedlak, Lindsay, 1968; Matkovics, Szabo, Varga, 1988).

\section{Preparation of isolated rat thoracic aortic rings}

Thoracic aorta samples collected at necropsy were immediately removed to be cleaned of the adhering connective tissue and fat. The samples were cut into rings approximately 3-4 $\mathrm{mm}$ in length. The aortic rings were immersed in a $10 \mathrm{ml}$ chamber bath which contained Krebs solution (composition, $\mathrm{mM}$ : $\mathrm{mM}$ : $\mathrm{NaCl} 119, \mathrm{KCl} 4.75$, $\mathrm{KH}_{2} \mathrm{PO}_{4} 1.2, \mathrm{NaHCO}_{3} 25, \mathrm{MgSO}_{4} 1.5, \mathrm{CaCl}_{2} 2,5$, glucose $11, \mathrm{pH} 7.3)$, maintained at a $37^{\circ} \mathrm{C}$, mounted on steel and oxygen $(95 \%)$ and $\mathrm{CO}(5 \%)$ was continuously bubbled through it. A resting tension of $1 \mathrm{~g}$ was applied to each tissue and equilibrated at least $1 \mathrm{~h}$. During the equilibrium period, the Krebs solution was changed every $15 \mathrm{~min}$. After equilibration, endothelial integrity was verified with a sub-maximal pre-contraction of phenylephrine hydrochloride $(\mathrm{PH})\left(10^{-9}-10^{-5} \mathrm{M}\right)$ and KCI (20-80 $\left.\mathrm{mM}\right)$. After the tension was stabilised, ACh $\left(10^{-8}-10^{-5} \mathrm{M}\right)$ was directly added into the chamber bath. Relaxation of the rings was considered indicative of an endothelium-intact ring. Relaxation was calculated as a percentage of the maximal contraction induced by $\mathrm{PH}$. Changes in tension were detected using isometric force transducers (ELJS045C-EMKA-R04003 ve R04004).

\section{Histopathology}

Tissue samples of the pancreas and thoracic aorta were collected at necropsy, and fixed in $10 \%$ phosphate buffered formaldehyde solution, and then embedded in paraffin. Tissue sections at $5 \mu$ thickness were cut 
and stained routinely with hematoxylin and eosin for microscopic examination.

\section{Immunohistochemistry}

Insulin/proinsulin expression in pancreas and inducible nitric oxide synthase (iNOS) activity in thoracic aorta tissues were investigated using the streptavidin biotin immunoperoxidase complex method with $3.3^{\prime}$-diaminobenzidine tetrahydrochloride as the chromogen. Anti-insulin/proinsulin antibody (Thermofisher Scientific, Catalog No: MA1-16710) and anti-iNOS polyclonal antibody (Lab Vision, Catalog No: RB9242P) were used in 1:500 dilutions with $1 \mathrm{~h}$ incubation times. Antigen retrieval was provided by microwave treatment in $0.1 \mathrm{M}$ sodium citrate solution ( $\mathrm{pH} 6.0$ ). Negative controls were provided by omitting the primer antibodies. All tissue sections were examined under a light microscope. A semi-quantitative (negative, weak, moderate, or strong immunoreactivity) grading system was used to score the degree of cell immunoreactivity.

\section{RESULTS AND DISCUSSION}

Normal pancreas histomorphology was observed in the NC group (Figure 1A a). Islets of Langerhans and acini were also structurally unremarkable. While in rats administered STZ+NAD (DC group), fewer and smaller islets were noted, with some cases revealing a complete absence. Occasional hydropic and granular degeneration in islets and no involvement of acini were noted in this group (Figure 1A b). The CN 500, CN 1000, CN 1500 groups all revealed varying degrees of pancreatic degeneration (Figure 1A c-e). Finally, the M group
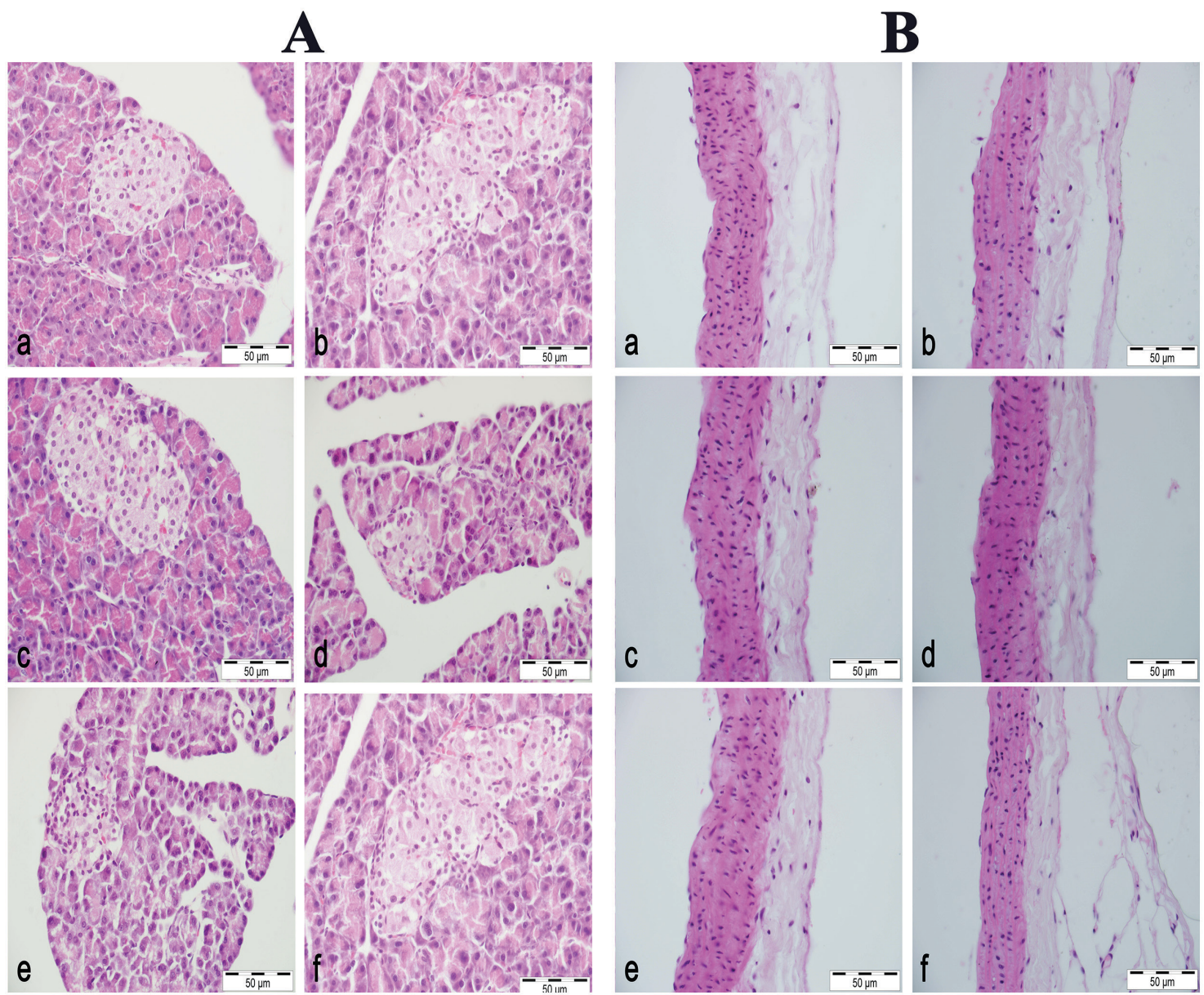

FIGURE 1 - A: Pancreas a) Normoglycemic Control group: Normal pancreas histomorphology, b) Diabetes control group: Significant amount of hydropic degeneration in the islet of Langerhans with some necrosis, c-e) Diabetes + Extract groups; 500, 1000 and $1500 \mathrm{mg}$, respectively: Some hydropic degeneration in the islet of Langerhans, and f) Metformin group: Weak degeneration. B: Thoracic aorta a) Normoglycemic Control group: Normal aorta histomorphology, b) Diabetes control group: No evident histopathological changes, c-e) Diabetes + Extract groups; 500, 1000 and $1500 \mathrm{mg}$, respectively: No histopathological changes and f) Metformin group: No pathology. 
revealed histopathological changes in the pancreas similar to the DC group (Figure 1A f). Microscopic examination of the tissue sections of thoracic aorta from all groups revealed no histopathological changes(Figure 1B a-f).

In the $\mathrm{NC}$ group, insulin/proinsulin immunoreactivity in pancreas tissue samples was high, illustrated by the heavy immunostaining of the islets of Langerhans (Figure 2A a). In DC group, few cells in the islets demonstrated immunoreactivity (Figure 2A b). Insulin/proinsulin immunoreactivity of the CN 500, CN 1000 and CN 1500 generally resembled that of the DC group, presenting mostly weak immunostaining(Figure $2 \mathrm{~A} \mathrm{c}$-e). There were no differences between the groups in terms of the immunoreactivity. Immunostaining in the $\mathrm{M}$ group was also no different than the DC group (Figure 2A f). Weak
iNOS immunoreactivity in the tunica adventitia and occasionally in the tunica media was also observed in the NC group. Little immunoreactivity was noted in the tunica intima of the thoracic aorta samples in the NC group (Figure 2B a). While the DC group revealed strong immunoreactivity in almost all cells of the tunica intima and tunica media. Most of the cells in the tunica media also had strong immunoreactivity in this group (Figure $2 \mathrm{~B}$ b). In the diabetes + extract groups (CN 500, CN 1000, CN 1500), iNOS immunoreactivity pattern in the thoracic aorta sections were similar to those observed in the DC group. However, immunostaining was generally moderate to strong, and comparably fewer cells showed immunoreactivity in these groups (Figure 2B c-e). There seemed to be no significant difference among the treatment
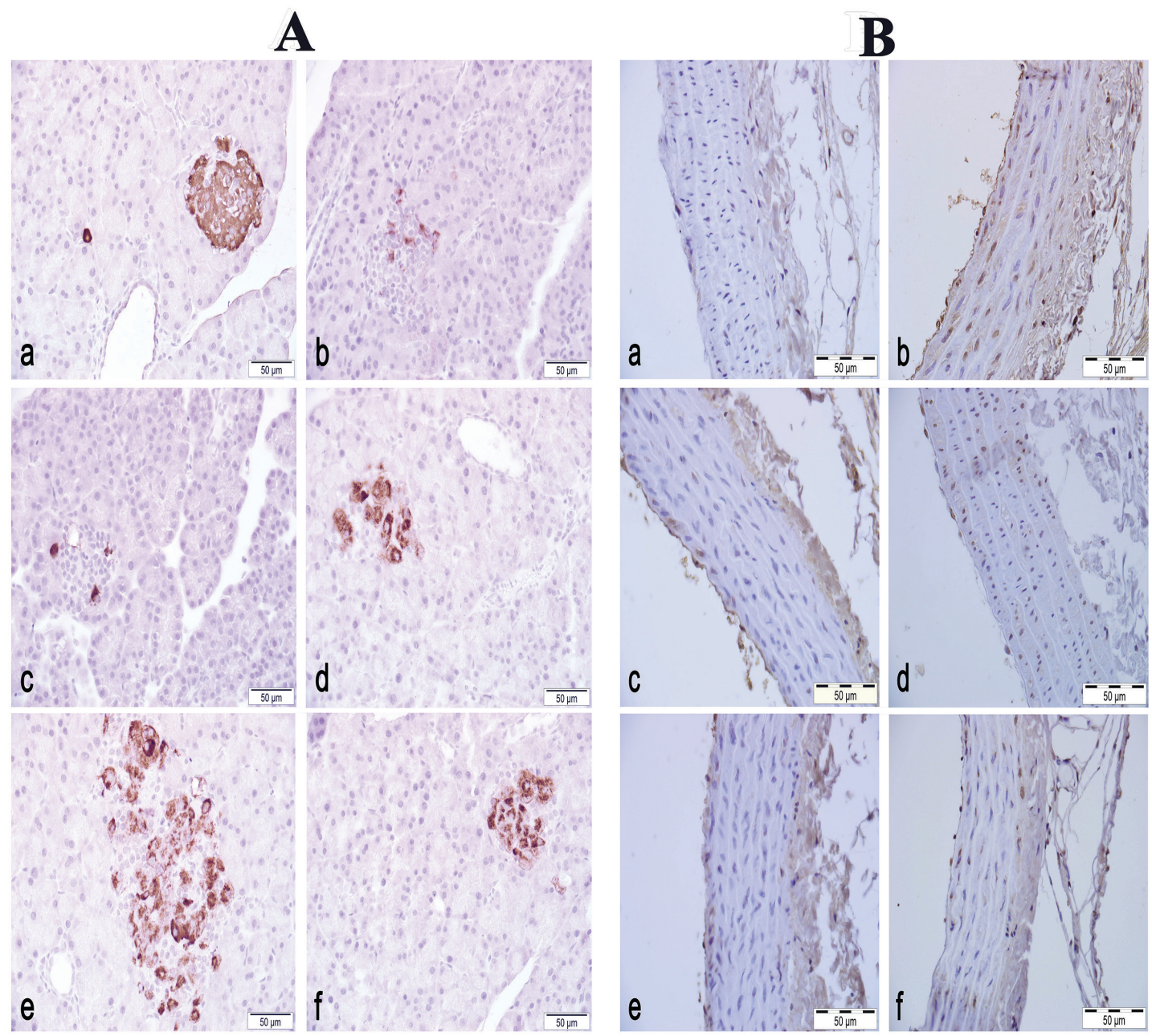

FIGURE 2 - A: Pancreas, insulin/proinsulin immunohistochemistry a) Normoglycemic Control group: strong immunoreactivity in the islet of Langerhans, e) Diabetes group: Weak immunoreactivity in few cells, c-e) Diabetes + Extract groups; 500, 1000 and $1500 \mathrm{mg}$, respectively: Weak immunoreactivity in few cells in the islet, and f) Metformin group: Weak immunoreactivity in few cells B: Thoracic aorta, inducible nitric oxide synthase (iNOS) immunohistochemistry a) Normoglycemic Control group: Mostly weak immunoreactivity located only in the tunica adventitia, b) Diabetes control group: Strong immunoreactivity in all three layers c-e) Diabetes + Extract groups; 500, 1000 and $1500 \mathrm{mg}$, respectively: moderate to strong immunoreactivity in all three layers of the thoracic aorta, and f) Metformin group: Strong immunoreactivity. 
groups as well. Thoracic aorta iNOS activity in the M group resembled to those of the DC group (Figure 2B f).

The contractile responses of aortic rings to cumulative concentrations of $\mathrm{PH}\left(10^{-9}\right.$ to $\left.10^{-5} \mathrm{M}\right)$ are shown in Figure 3. The Cinnamomum cassia extract (CN500, $\mathrm{CN} 1000$ and $\mathrm{CN} 1500)$ and $\mathrm{M}$ significantly decreased the contractile responses to higher concentrations of $\mathrm{PH}\left(10^{-7}\right.$ $10^{-6}$ and $\left.-10^{-5} \mathrm{M}\right)$ compared to $\mathrm{DC}(\mathrm{p}<0.05)$ (Figure $\left.3 \mathrm{~A}\right)$. In aortic rings pre-contracted with $\mathrm{PH}, \mathrm{ACh}$ relaxation was impaired in the DC group The relaxation response to ACh $10^{-8}-10^{-5} \mathrm{M}$, was increased in $\mathrm{CN} 1000, \mathrm{CN}$ 1500 , and $\mathrm{M}$ groups as compared to group $\mathrm{DC}(\mathrm{p}<0.05)$, (Figure 3B).

A significant increase in the MDA level was observed in group DC when compared to the $\mathrm{NC}(\mathrm{p}<0.05)$. Both the CN 500 and $\mathrm{M}$ groups revealed significantly lower aorta MDA levels compared to group DC, $\mathrm{p}<0.05$ (Figure 4A). Aorta GSH levels were also significantly lower in group $\mathrm{DC}$ as compared to the $\mathrm{NC}(\mathrm{p}<0.01)$. Aorta GSH levels were significantly higher in all $\mathrm{CN}$ treatment groups and $\mathrm{M}$ group compared to group $\mathrm{DC}(\mathrm{p}<0.05, \mathrm{CN}$ $500(\mathrm{p}<0.01))$ (Figure 4B). The levels of GPx in the aorta were significantly increased in CN 500, CN 1000, CN 1500 and $\mathrm{M}$ groups as compared to group $\mathrm{DC}(\mathrm{p}<0.05)$ (Figure 4C). The level of aorta NO was significantly higher in group DC as compared to those of the NC group $(p<0.001)$ and remaining groups $(p<0.05)$. Aorta NO levels were significantly decreased in the CN 500, CN $1000, \mathrm{CN} 1500$ and M groups compared to DC $(\mathrm{p}<0.01)$ (Figure 4D).

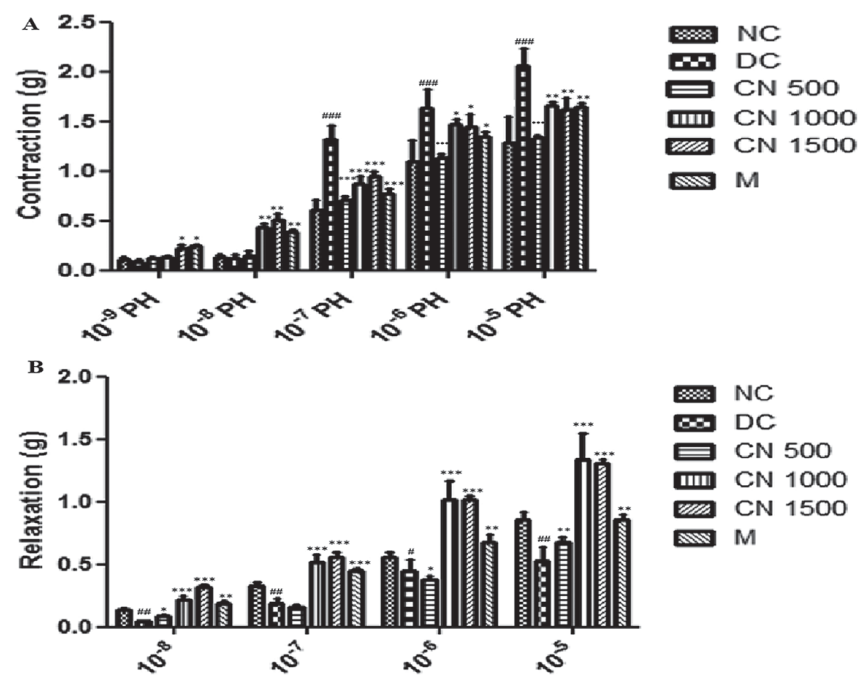

FIGURE 3 - (A) The contractile response of aortic rings to cumulative concentrations of phenylepherine (10-9 - 10-5 $\mathrm{M})$ and (B) relaxation response of aortic rings to cumulative concentrations of Ach (10-8 - 10-5 M) in Normoglycemic Control (NC), Diabetes control group (DC), Cinnamomum cassia extract (CN 500, CN 1000, and CN 1500), and metformin (M) treated groups. Values are presented as means \pm SEM, * and $\#=\mathrm{p}<0.05, * *$ and $\# \#=\mathrm{p}<0.01$, *** and $\# \# \#=\mathrm{p}<0.001,(\mathrm{n}=10)$.
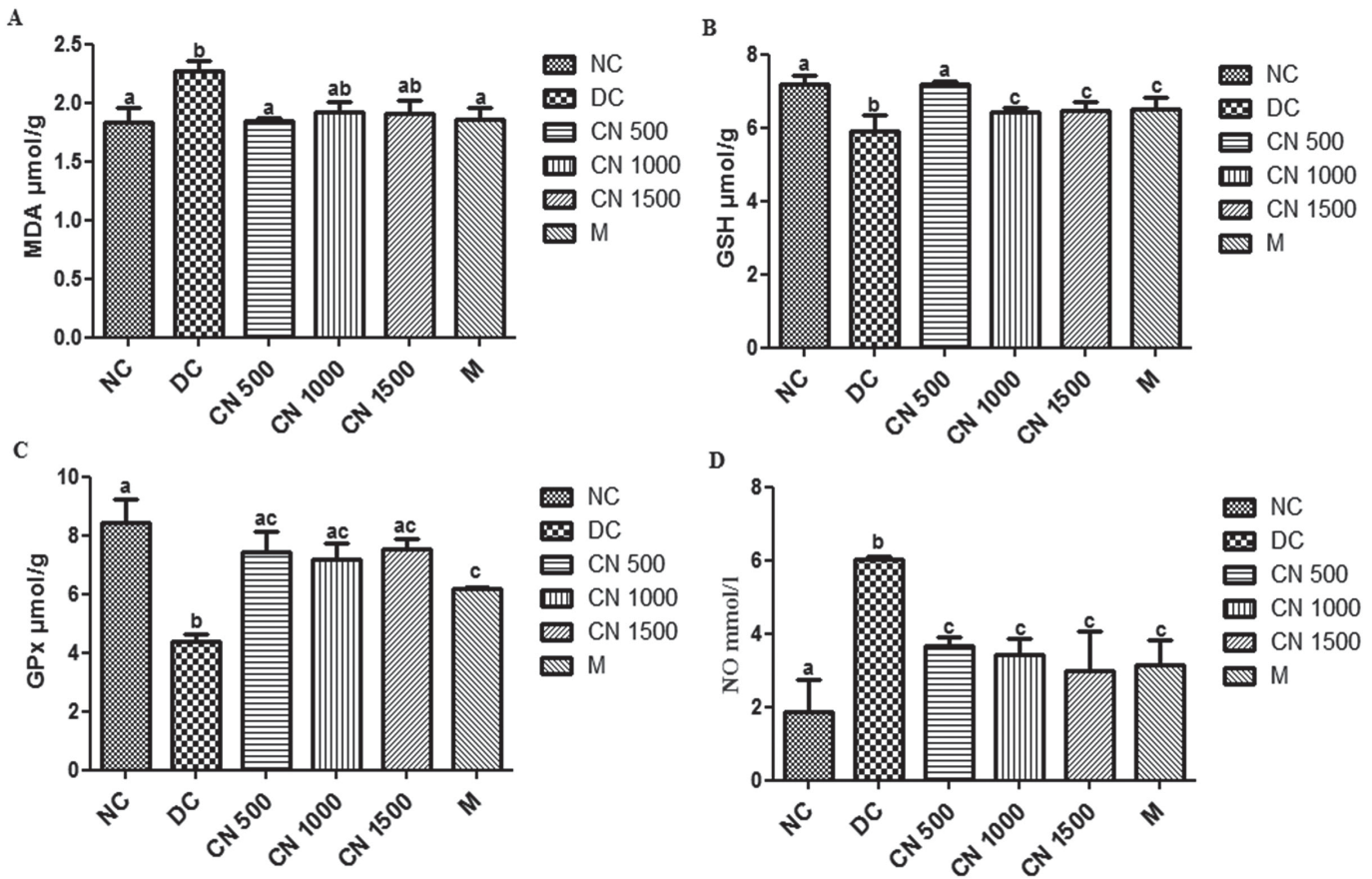

FIGURE 4 - The aorta MDA (A), GSH (B), GPx (C) levels and NO (D) activitiy in experimental groups (a-b-c=p $<0.05$ (A), $a-b=p<0.01, a-c=p<0.05, b-c=p<0.05$ (B and C), $a-b=p<0.001, b-c=p<0.01, a-c=p<0.05$ (D) $n=10$ there is no statistical difference among the groups expressed the with same letters). 
Increased free radicals in hyperglycemic conditions have been reported to react with NO resulting in the formation strong oxidants like peroxynitrite and nitrotyrosine. These strong oxidants may cause cytotoxic effects in the heart and vessels (Flesch et al., 1999; Nagareddy et al., 2005). Although decreased endothelial NO expression due to endothelial dysfunction has been noted, increased NO in diabetes may be consequent to iNOS and neuronal nitric oxide synthase (nNOS) (Nagareddy et al., 2005). Previous studies have shown that iNOS expression is increased in cardiomyocytes of diabetic rats (Smith, Paulson, Romano, 1997) and in platelets of type I-type II diabetic patients (Tannous et al., 1999). Therefore, it is stated that the investigation of iNOS activity is very important in understanding the mechanism of endothelial and vascular dysfunction associated with long-term hyperglycemia in recent years (Bardell, MacLeod, 2001). In the present study, strong iNOS immunoreactivity was detected in all three layers (tunica intima, tunica media, tunica adventitia) in DC group. Goswami et al. (2014) indicated that the C. cassia extract inhibits arginase activity and enhances sexual function. However, studies have already shown that increased expression of iNOS during inflammation suppresses arginase II expression (Carraway et al., 1998). In addition, other studies have reported that aldose reductase inhibitors (ferulic acid, cinnamaldehyde) or arginase inhibitors (citrulline, norvaline, ornithine) have no effect on blood sugar levels and lack hypoglycaemic effects (Waleed Barakat, Askar, Fahmy, 1998). In this study, we believe that the C. cassia extract decreased NO levels by reducing hyperglycemia and consequently iNOS activity.

However, moderate immunoreactivity was detected in $\mathrm{CN}$ extract-treated groups. Type II diabetes is characterised by insulin resistance and is associated by improved insulin secretion disorders and decreased beta cell mass due to prolonged hyperglycemia (Butler et al., 2003). It is also stated that amylin accumulates in islets in type 2 diabetes, and cause apoptosis in beta cells (Lorenzo et al., 1994). CN extract did not alter insulin/proinsulin levels in the pancreas.

In the study, it was determined that decreased antioxidant levels (GSH, GPx) due to diabetes on the thoracic aorta were significantly increased in the $\mathrm{CN}$ extract group (CN 500, CN 1000, CN 1500), and NO levels were decreased significantly. Although it is expected that decreased endothelial production of NO is due to endothelial damage, iNOS and nNOS are thought to be the source of increasing NO. Nagareddy et al. (2005) suggested that impaired endothelial function in rats with Type I diabetes is associated with increased iNOS and eNOS expression in cardiovascular tissues. Noori, Azmat and Mahboob (2012) determined that garlic and cinnamon significantly reduced MDA levels in the heart. Badalzadeh et al. (2014) showed a significant decrease in serum MDA in the cinnamon extract-administered groups. Further, cinnamaldehyde, one of the key components of C. cassia, has been reported to have antioxidant and antiinflammatory effects.

The results of this study show that administration of $C$. cassia extract increases aortic reactivity in response to vasoconstrictor and vasodilator agents in rats with type II diabetes. Cinnamaldehyde has been shown to cause relaxation of noradrenaline, potassium and prostaglandin F2a-induced aortic contraction (Xu et al., 2006; Xue et al., 2011). It has been determined by Yanaga et al. (2006) that cinnamaldehyde stimulates endothelial NO synthesis in the isolated aorta. Abebe et al (Abebe, Harris, Macleod, 1990) have shown that the vascular response to $\alpha-1$ adrenoceptor agonists differs from that of diabetic animals. The increased kinking responses may be due to increased myofilament $\mathrm{Ca}^{2+}$ sensitivity (Kizub et al., 2010), increased susceptibility to oxidative stress (Tabit et al., 2010), and increased calcium flux with voltagesensitive L-type $\mathrm{Ca}^{2+}$ channels (Pinho et al., 2010), resulting in impaired endothelial function (Potenza et al., 2009). The adrenoreceptor agonist, $\mathrm{PH}$, causes $\mathrm{Ca}^{2+}$ flow through receptor-mediated $\mathrm{Ca}^{2+}$ channels and contraction in the aortic area by $\mathrm{Ca}^{2+}$ release from the sarcoplasmic reticulum (Thorneloe, Nelson, 2005; Mccarron et al., 2003). Thorneloe and Nelson (2005) stated that PH stimulation of phospholipase $\mathrm{C}$ with the production of diacylglycerol and 1,4,5 triphosphate inositol and then has been activated the light chain of myosin with DG protein kinase $\mathrm{C}$ activation. Thus, contraction is occurred which with $\mathrm{Ca}^{2+}$ release from the sarcoplasmic reticulum after induction of IP3 receptors. Moreover, voltage-dependent $\mathrm{Ca}^{2+}$ channels are responsible for $\mathrm{KCl}$-dependent contractions. Zhang et al. (2011) demonstrated that the $\mathrm{CN}$ effect on $\mathrm{PH}$ and $\mathrm{KCl}$-induced vasoconstriction of diabetic rat aortic rings may be due to these effects. These effects of $\mathrm{CN}$ were reported that the formation and release of EDRFs including endothelial-derived hyperpolarising factor, NO and prostacyclin in the endothelial cells of the vascular bed by ACh in the vascular smooth muscle may causes an endothelium-dependent relaxation.

\section{CONCLUSION}

Neuropathy, nephropathy and retinopathy are the first to come to mind when chronic complications of type II diabetes are mentioned. Cardiovascular disorders and 
endothelial damage mechanisms are generally ignored. This study indicates that 35 days of oral intake of varying doses of CN extract, reduced iNOS immunreactivity, oxidative stress and inflammation in the thoracic aorta of rats. Further, $\mathrm{CN}$ treatment was shown to have a positive effect on the impaired contraction mechanism in the thoracic aorta of rats with type II diabetes mellitus. However, insulin/proinsulin immunoreactivity did not change.

\section{CONFLICTS OF INTEREST}

The authors declare no conflicts of interest and are responsible for the contents of this research.

\section{ACKNOWLEDGMENT}

This research was supported by the Scientific Research Project Coordination of Kafkas University KarsTurkey (2015-TS-90).

\section{REFERENCES}

Abebe W, Harris KH, Macleod KM. Enhanced contractile responses of arteries from diabetic rats to alpha 1-adrenoceptor stimulation in the absence and presence of extracellular calcium. J Cardiovasc Pharmacol. 1990;16(2):239-248.

Badalzadeh R, Shaghaghi M, Mohammadi M, Dehghan G, Mohammadi Z. The effect of cinnamon extract and long-term aerobic training on heart function, biochemical alterations and lipid profile following exhaustive exercise in male rats. Adv Pharm Bull. 2014;4(2):515-520.

Barceloux DG. Cinnamon (cinnamomum species). Disease-aMonth. 2009;55(6):327-335.

Bardell AL, MacLeod KM. Evidence for inducible nitricoxide synthase expression and activity in vascular smooth muscle of streptozotocin-diabetic rats. J Pharmacol Exp Ther. 2001;296(2):252-259.

Butler AE, Janson J, Bonner-Weir S, Ritzel R, Rizza RA, Butler PC. $\beta$-Cell deficit and increased $\beta$-cell apoptosis in humans with type 2 diabetes. Diabetes. 2003;52(1):102-110.

Carraway MS, Piantadosi CA, Jenkinson CP, Huang YCT. Differential expression of arginase and iNOS in the lung in sepsis. Exp Lung Res. 1998;24(3):253-268.
De Vriese AS, Verbeuren TJ, Van de Voorde J, Lameire NH, Vanhoutte PM. Endothelial dysfunction in diabetes. Brit J Pharmacol. 2000;130(5):963-974.

Flesch M, Kilter H, Cremers B, Laufs U, Sudkamp M, Ortmann $\mathrm{M}$, et al. Effects of endotoxin on human myocardial contractility involvement of nitric oxide and peroxynitrite. J Am Coll Cardiol. 1999;33(4):1062-1070.

Furchgott RF, Vanhoutte PM. Endothelium derived relaxing and contracting factors. FASEB J. 1989;3(9):2007-2018.

Goswami SK, Inamdar MN, Jamwal R, Dethe S. Effect of Cinnamomum cassia methanol extract and sildenafil on arginase and sexual function of young male Wistar rats. J Sexual Med. 2014;11(6):1475-1483.

Imparl-Radosevich J, Deas S, Polansky MM, Baedke DA, Ingebrutsen TS, Anderson RA, et al. Regulation of phosphorylase phosphatase (PTP-1) and insulin receptor kinase by fractions from cinnamon: implications for cinnamon regulation of insulin signaling. Horm Res. 1998;50(3):177-182.

Jarvill-Taylor KJ, Anderson RA, Graves DJ. A hydroxychalcone derived from cinnamon functions as a mimetic for insülin in 3T3-L1 adipocytes. J Am Coll Nutr. 2001;20(4):327-336.

Kiff RJ, Gardiner SM, Compton AM, Bennett T. Selective impairment of hindquarters vasodilator responses to bradykinin in conscious wistar rats with streptozotocin-induced diabetes mellitus. Brit J Pharmacol. 1991;103(2):1357-1362.

Kizub IV, Pavlova OO, Johnson CD, Soloviev AI, Zholos AV. Rho kinase and protein kinase $\mathrm{C}$ involvement in vascular smooth muscle myofilament calcium sensitization in arteries from diabetic rats. Brit J Pharmacol. 2010;159(8):1724-1731.

Lorenzo A, Razzaboni B, Weir GC, Yankner BA. Pancreatic islet cell toxicity of amylin associated with type 2 diabetes mellitus. Nature. 1994;368(6473):756-760.

Macías M, Ahedo D, Bobadilla R, Martínez F, Mera E, Padilla $\mathrm{I}$, et al. NADPH oxidase inhibitors as regulators of vascular relaxation in aortic rings of diabetic rats with streptozotocin (LB539). FASEB J. 2014;28(1):LB539.

Masiello P, Broca C, Gross R, Roye M, Manteghetti M, HillaireBuys D. Experimental NIDDM: development of a new model in adult rats administered streptozotocin and nicotinamide. Diabetes. 1998;47(2):224-229. 
Matkovics B, Szabo L, Varga I. Determination of enzyme activities in lipid peroxidation and glutathione pathways (in Hungarian). Laboratoriumi Diagnosztika. 1988;15:248-250.

Mayhan WG, Simmons LK, Sharpe GM. Mechanisms of impaired responses of cerebral arterioles during diabetes mellitus. Am J Physiol. 1991;260(2):319-326.

Mccarron JG, Bradley KN, Macmillan D, Muir TC. Sarcolemma agonist-induced interactions between InsP3 and ryanodine receptors in $\mathrm{Ca} 2+$ oscillations and waves in smooth muscle. Biochem Soc Trans. 2003;31(Pt 5):920-924.

Miranda KM, Espey MG, Wink DA. A rapid, simple spectrophotometric method for simultaneous detection of nitrate and nitrite. Nitric Oxide Biol Chem. 2001;5(1):62-71.

Nagareddy PR, Xia Z, McNeill JH, MacLeod KM. Increased expression of iNOS is associated with endothelial dysfunction and impaired pressor responsiveness in streptozotocin-induced diabetes. Am J Physiol-Heart Circul Physiol. 2005;289(5):21442152.

Nitenberg A, Valensi P, Sachs R, Dali M, Aptecar E, Attali JR. Impairment of coronary vascular reserve and $\mathrm{ACh}$-induced coronary vasodilation in diabetic patients with angiographically normal coronary arteries and normal left ventricular systolic function. Diabetes. 1993;42(7):1017-1025.

Noori S, Azmat M, Mahboob T. Study on antioxidant effects of cinnamon and garlic extract in liver, kidney and heart tissue of rat. Biosci Res. 2012;9(1):17-22.

Pinho JF, Medeiros MA, Capettini LS, Rezende BA, Campos PP, Andrade SP. Phosphatidylinositol 3-kinase-delta up-regulates L-type $\mathrm{Ca} 2+$ currents and increases vascular contractility in a mouse model of type 1 diabetes. Brit J Pharmacol. 2010;161(7):1458-1471.

Placer ZA, Cushman LL, Johnson BC. Estimation of product of lipid peroxidation (malonyl dialdehyde) in biochemical systems. Anal Biochem. 1966;16(2):359-364.

Potenza MA, Gagliardi S, Nacci C, Carratu MR, Montagnani M. Endothelial dysfunction in diabetes: from mechanisms to therapeutic targets. Curr Med Chem. 2009;16(1):94-112.

Scirica BM, Bhatt DL, Braunwald E, Steg PG, Davidson J, Hirshberg B, Ohman B, et al. Cavender, Saxagliptin and cardiovascular outcomes in patients with type 2 diabetes mellitus. New Engl J Med. 2013;369(14):1317-1326.
Sedlak J, Lindsay RH. Estimation of total, protein-bound, and nonprotein sulfhydryl groups in tissue with Ellman's reagent. Anal Biochem. 1968;25:192-205.

Smith JM, Paulson DJ, Romano FD. Inhibition of nitric oxide synthase by L-NAME improves ventricular performance in streptozotocin-diabetic rats. J Mol Cell Cardiol. 1997;29(9):2393-2402.

Tabit CE, Chung WB, Hamburg NM, Vita JA. Endothelial dysfunction in diabetes mellitus: molecular mechanisms and clinical implications. Rev Endocr Metab Disord. 2010;11(1):6174.

Tannous M, Rabini RA, Vignini A, Morretti H, Fumelli P, Zielinski B, et al. Evidence for iNOS-dependent peroxynitrite production in diabetic platelets. Diabetologia. 1999;42(5):539544.

Thorneloe KS, Nelson MT. Ion channels in smooth muscle: regulators of intracellular calcium and contractility. Can J Physiol Pharmacol. 2005;83(3):215-242.

WaleedBarakat RH, Askar M, Fahmy A. Role of aldose reductase and arginase inhibitors in diabetic vascular and behavioral complications. Zagazig J Pharm Sci. 1998;23(1):58-72.

Williams SB, Cusco JA, Roddy MA, Johnstone MT, Creager MA. Impaired nitric oxidemediated vasodilation in patients with non-insulin-dependent diabetes mellitus. J Am Coll Cardiol. 1996;27(3):567-574.

$\mathrm{Xu}$ J, Zou MH. Molecular insights and therapeutic targets for diabetic endothelial dysfunction. Circulation. 2009;120(13):1266-1286.

Xu M, Yu L, Ding YY, Wang YM, Wang SW, Pei JM. Experimental study on hypotensive effects of cinnamaldehyde in anesthetized rats. Chin Heart J. 2006;18:272-276.

Xue YL, Shi HX, Murad F, Bian K. Vasodilatory effects of cinnamaldehyde and its mechanism of action in the rat aorta. Vasc Health Risk Manag. 2011;7:273-280.

Yanaga A, Goto H, Nakagawa T, Hikiami H, Shibahara N, Shimada Y. Cinnamaldehyde induces endothelium-dependent and-independent vasorelaxant action on isolated rat aorta. Biol Pharm Bull. 2006;29(12):2415-2418. 
Effects of Cinnamomum cassia extract on oxidative stress, immunreactivity of iNOS and impaired thoracic aortic reactivity induced by type II diabetes in rats

Zhang LN, Vincelette J, Chen D, Gless RD, Anandan SK, Rubanyi GM. Inhibition of soluble epoxide hydrolase attenuates endothelial dysfunction in animal models of diabetes, obesity and hypertension. Eur J Pharmacol. 2011;654(1):68-74.
Zou MH, Cohen R, Ullrich V. Peroxynitrite and vascular endothelial dysfunction in diabetes mellitus. Endothelium. 2004;11(2):89-97.

Received for publication on $30^{\text {th }}$ November 2017 Accepted for publication on $17^{\text {th }}$ January 2018 